\title{
Gamma irradiation and steam pretreatment of jute stick powder for the enhancement of dye adsorption efficiency
}

\author{
Fahmida Parvin $^{1}$ Nargis Sultana ${ }^{1} \cdot$ S. M. Ahsan Habib $^{2} \cdot$ Nikhil Chandra Bhoumik $^{3}$
}

Received: 4 May 2015/Accepted: 7 September 2017/Published online: 12 September 2017

(C) The Author(s) 2017. This article is an open access publication

\begin{abstract}
The aim of this study is to find out the facile and effective pretreatment technique to enhance the capacity of jute stick powder (JSP) in adsorbing dye from raw textile effluent. Hence, different pretreatment techniques, i.e., radiation treatment, alkali treatment, ammonia treatment, steam treatment and $\mathrm{CaCl}_{2}$ treatment were applied to JSP and the adsorbing performance were examined for synthetic dye solutions (Blue FCL and Red RL dye). Different gamma radiation doses were applied on JSP and optimum dye removal efficiency was found at $500 \mathrm{krad}$ in removing these two dyes $(50 \mathrm{ppm})$ from solutions. Among the different pretreatment techniques, gamma irradiated JSP (500 Krad) exhibits highest dye uptake capacity for RED RL dye, whereas steam-treated JSP shows highest performance in adsorbing blue FCL dye. Subsequently, we applied the gamma irradiated and steam-treated JSP on real textile effluent (RTE) and these two techniques shows potentiality in adsorbing dye from raw textile effluent and in reducing $\mathrm{BOD}_{5}, \mathrm{COD}$ load and TOC to some extent as well. Fourier transform infrared spectroscopy (FTIR) analysis also proved that dye has been adsorbed on pretreated JSP.
\end{abstract}

Publisher's Note Springer Nature remains neutral with regard to jurisdictional claims in published maps and institutional affiliations.

Fahmida Parvin

fahmidaprvn497@gmail.com

1 Department of Environmental Sciences, Jahangirnagar University, Dhaka 1342, Bangladesh

2 Bangladesh Space Research and Remote Sensing Organization, Dhaka 1207, Bangladesh

3 Wazed Miah Science Research Centre, Jahangirnagar University, Dhaka 1342, Bangladesh
Keywords Jute stick powder pretreatment - Textile wastewater - Gamma radiation

\section{Introduction}

Many industries, such as the textile, printing, and leather industries uses different types of dyes and discharge colored wastewaters and dyes that remain in the effluents, undergo chemical changes, consume dissolved oxygen, and may cause carcinogenic and genotoxic effects (Crini 2006). Dyes with striking visibility in recipients may significantly affect photosynthetic activity in aquatic environment due to the reduced light penetration (Fu and Virarahavan 2001). It is estimated that over $10 \%$ of dye used in textile processing does not bind to the fibers and is, therefore, released to the environment (Hildenbrand et al. 1999).

Numerous methods have been evolved to decolorize wastewater, but still now none of the methods is perfectly treating dye containing wastewater as most of the dyes have complex aromatic structure of synthetic origin and thus hardly amenable to biodegradation (Chatterjee et al. 2005). In chemical methods, coagulation produces high concentration of sludge which results in secondary pollution problem because excessive chemicals have to be added in treatment processes. Physical treatment methods require high energy and cause formation of hazardous by-products. Sometimes it requires regeneration or disposal (Saraswathi and Balakumar 2009). In one of our previous work, we used ionizing radiation (known as electron beam and gamma radiation), which is promising for the treatment of textile dye solution as it produce zero waste (Parvin et al. 2015), but one of the limitation of this methods is its high cost.

Adsorption technology is considered as one of the most effective methods for the removal of dyes present in 
effluents. Activated carbon is the most used adsorbent to remove dye from the effluent. However, due to its high cost and considering the huge quantities of wastewater to be treated, efforts have been made to use the bio-adsorbents of considerable lower cost. In the last several years, special emphasis on the use of several agricultural waste products like jute, sugarcane baggage, chitosan has been given due to the growing interest in low cost adsorbents (Senthilkumaar et al. 2006; Panda et al. 2009; Islam et al. 2013; Kadam et al. 2013). Hence, Jute stick powder (JSP) can be used as a potential biomass for dye adsorbent from the effluent as it is abundant in the south Asian countries (Panda et al. 2009; Islam et al. 2013). Moreover, it is possible to enhance the adsorbing capacity of the JSP by applying different pretreatment method which may results in the change in surface chemical characters or radicals. In this study, JSP has been pretreated by several methods to enhance the dye absorption capacity and applied on real textile effluent (RTE) to observe the change in color and other parameters.

\section{Experimental}

\section{Materials}

Blue FCL and Red RL dye used in this study were purchased from BDH, England. All other chemicals and reagents were procured from Merck, Germany.

\section{Preparation of biosorbent}

Jute sticks were collected from the local area, then they were cut into small pieces, and having washed with water properly to remove adhering substances, they were dried at room temperature. Finally, with the help of a blender, this was powdered by grinding and then sieved. The pore size of the sieve was $1.180 \mathrm{~mm}$. The scanning electron microscope image of jute stick powder (JSP) has taken by JSM630 JEOL, Japan, prior to observe the surface morphology of the JSP. SEM image of the grinded JSP (Fig. 1) is found to be smooth and layered structure over a large area and very much consistent with other author's finding (Panda et al. 2009).

\section{Collection of real textile effluent}

Real textile effluent was collected from the equalization tank of a textile industry located in Dhaka Export Processing Zone, Bangladesh. The sample was a mixture of wastewater, discharged from several sections such as washing, dying, waxing and rinsing.

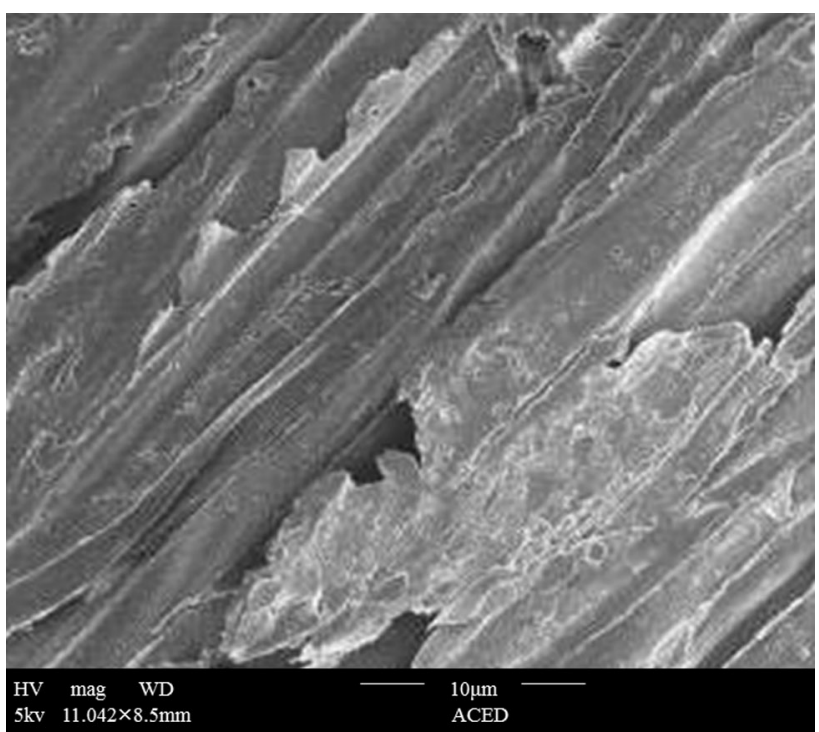

Fig. 1 SEM image of grinded JSP

\section{Different pretreatments to jute stick powder}

Irradiation by gamma ray

Jute stick powder was irradiated by gamma rays from the cobalt-60 gamma radiation source at an absorbed dose of (100-1000) krad. The dose was determined by Amber Perspex dosimeter; type $3042 \mathrm{~F}$.

\section{$\mathrm{CaCl}_{2}$ pretreatment}

Jute stick powder ( $2 \mathrm{~g}$ ) was added separately in the $0.2 \%$ concentrations of $\mathrm{CaCl}_{2}$ and incubated at $100{ }^{\circ} \mathrm{C}$ for $24 \mathrm{~h}$. The dried JSP was used for further adsorption study.

\section{Alkali pretreatment}

Jute stick powder ( $2 \mathrm{~g}$ ) was added to $3 \mathrm{M} \mathrm{NaOH}$ solution and kept it for $3 \mathrm{~h}$. After this treatment the samples were neutralized with $\mathrm{HCl}$. Then it was washed thoroughly with distilled water and dried at $80{ }^{\circ} \mathrm{C}$ in an oven to obtain a constant weight.

\section{Ammonia steeping}

Two grams of JSP was added to a solution containing $4 \mathrm{M}$ $\mathrm{NH}_{4}-\mathrm{OH}$ and kept it in an orbital shaker $120 \mathrm{rpm}$ for $24 \mathrm{~h}$ at $22{ }^{\circ} \mathrm{C}$. Then it was filtered through Whatman filter paper and the treated JSP were washed with distilled water and dried to constant weight at $80{ }^{\circ} \mathrm{C}$ in oven. 


\section{Steam pretreatment}

Two grams of JSP was added in $50 \mathrm{~mL}$ of distilled water and autoclaved for $40 \mathrm{~min}$ at $121^{\circ} \mathrm{C}$. Then it was filtered by Whatman filter paper No. 1 and the residues were dried in an oven at $80{ }^{\circ} \mathrm{C}$ to obtain the constant weight.

\section{Experimental methodology used for the dye adsorption}

Adsorption studies were determined by batch contact system. The adsorption experiments were carried out by adding the differently pretreated dried adsorbent $(100 \mathrm{mg})$ in $50 \mathrm{~mL}$ dye $(50 \mathrm{mg} / \mathrm{L})$ solution (Red RL and Blue FCL) at room temperature in a $250-\mathrm{mL}$ conical flask. Flasks were then subjected to intermittent shaking for $1 \mathrm{~h}$ at $120 \mathrm{rpm}$ (rotation per min) for proper adsorption at a constant temperature $\left(30{ }^{\circ} \mathrm{C}\right)$ until the equilibrium was attained.

At the end of incubation, these solutions were filtered using Whatman filter paper and the absorbance of the filtrate was determined (at $\lambda_{\max }=617 \mathrm{~nm}$ for Blue FCL and $\lambda_{\max }=507 \mathrm{~nm}$ for Red RL) by UV spectrophotometer (Shimadzu, Japan, model 1240).

The percentage of dye uptake or removal was calculated by the following equation:

Percentage removal $(\%)=\left(C_{\mathrm{o}}-C_{\mathrm{f}}\right) / C_{\mathrm{o}} \times 100$

Where,

$C_{\mathrm{o}}=$ the initial liquid-phase concentration of dye.

$C_{\mathrm{f}}=$ the final liquid-phase concentration of dye.

Among all the pretreatment method the two methods which gave optimized dye adsorption efficiency were used for the treatment of RTE according to the same experimental method (100 mg adsorbent for $50 \mathrm{~mL}$ RTE). To determine the dye removal for RTE, the UV-Vis absorbance spectra at the wavelength of $200-600 \mathrm{~nm}$ was taken before and after the adsorption.

\section{Batch kinetics studies}

Before going to the experiment for RTE, it is important to know the reaction kinetics of dye absorption study. To determine the reaction kinetics, absorption studies were performed in a set of conical flasks $(250 \mathrm{~mL})$ where $50 \mathrm{~mL}$ of red RL solutions with initial concentration of $50 \mathrm{mg} / \mathrm{L}$ were placed in these flasks. Equal mass of $0.1 \mathrm{~g}$ of the prepared gamma irradiated and steam-treated JSP was added to each flask and kept in an isothermal shaker at $30{ }^{\circ} \mathrm{C}$. The aqueous samples were taken at preset time intervals (0-120 min) and the concentration of RED RL has been measured.

The dye concentrations in the experimental samples were evaluated from the calibration curves. Amount of dye uptake, $q(\mathrm{mg} / \mathrm{g})$, was calculated using the following equation:

$q=\left(C_{\mathrm{i}}-C_{\mathrm{f}}\right) V / W$

where $C_{\mathrm{i}}(\mathrm{mg} / \mathrm{L})$ is the initial dye concentration, $C_{\mathrm{f}}(\mathrm{mg} / \mathrm{L})$ is the dye concentration after adsorption, $W(\mathrm{~g})$ is the amount of biosorbent and $V(\mathrm{~L})$ is the volume of the solution. Similar study has also been done for Blue FCL dye.

\section{Tests of physico-chemical parameters of RTE and treated effluent}

After passing through pretreated JSP Physico-chemical parameters especially $\mathrm{pH}, \mathrm{EC}$, TDS and DO of RTE were measured using Portable Multiparameter (Model no-sensionTM 156, Supplier-Hatch Company USA, 2000) within half an hour of the collection of sample. The turbidity of the samples were measured by Turbidity Meter HANNA H193703 Microprocessor Turbidity Meter, range (0.00-1000) FTU (Formazin Turbidity Unit). The 5-day BOD test of the Samples was done following the standard method (ASTM-5210 B). The COD of the samples was determined by Closed Reflux, Colorimetric Method (ASTM-5220 D). Total organic carbon (TOC) has been measured by high temperature catalytic oxidation method (HTCO) with a TOC 5000A (Shimadzu, Japan) using potassium hydrogen phthalate (KHP) as a standard.

\section{Fourier transformed infrared spectroscope (FTIR)}

FTIR spectra were obtained for jute stick powder before and after the adsorption process by FTIR spectrophotometer (Perkin Elmer, UK). The FTIR spectrum was taken in a transmittance mode. The spectra were obtained at a resolution of $8 \mathrm{~cm}^{-1}$ in the range of $400-2000 \mathrm{~cm}^{-1}$. The samples were usually prepared with $\mathrm{KBr}$, in the form of disk. The pressed disks were prepared by grinding the powder specimens with IR grade $\mathrm{KBr}$ in an agate mortar.

\section{Results and discussion}

\section{Effect of gamma irradiation on the dye adsorption capacity of jute stick powder}

JSP was irradiated by different doses of gamma radiation to find out the optimum dose at which JSP showed highest adsorption for the dyes, e.g., Blue FCL and Red RL. The concentration used for this study was $50 \mathrm{ppm}$ of dye. It was found that JSP could adsorb around $60 \%$ of 
the two dyes when these were dissolved in a concentration of $50 \mathrm{ppm}$ at room temperature. In this study, four different absorbed doses (100, 250, 500 and $1000 \mathrm{krad})$ of gamma radiation were applied on JSP to reveal the effect of gamma radiation on the adsorption efficiency of JSP. For Blue FCL, JSP irradiated at $250 \mathrm{krad}$ showed the highest uptake capacity, whereas JSP irradiated at 500 krad showed the best adsorption results for Red RL compared to other doses (Fig. 2). Irradiation of lignocellulose material suggests some effects depending on the type of polymers, parameters of irradiation, the phase of material under processing and others. It is found that the effects of ionizing radiation on polymeric materials can be revealed in one of three major ways. When radiation is used, the polymer may undergo one or both of the two possible reactions: those that are molecular weight increasing in nature, or molecular weight reducing in nature. Or, in the case of radiation resistant polymers, no significant change in molecular weight will be observed (Wach et al. 2003). In general, cellulose and its derivatives irradiated with ionizing radiation in solid state or in dilute aqueous solution undergo mainly degradation by the cleavage of glycoside bonds in its main chain (Pekel et al. 2004).

It is seen that there is a good chance in dye uptake by gamma irradiated jute stick powder in comparison with the dye uptake by jute stick powder without any radiation treatment. So it can be assumed that there is a change in composition of jute stick powder after radiation treatment which enhances the dye uptake capacity. Here, JSP irradiated at $500 \mathrm{krad}$ also showed better adsorption capacity for Blue FCL which was closer to the highest one. Hence, in this study $500 \mathrm{krad}$ of gamma radiation was considered as the optimum radiation dose for the uptake of dye by JSP.

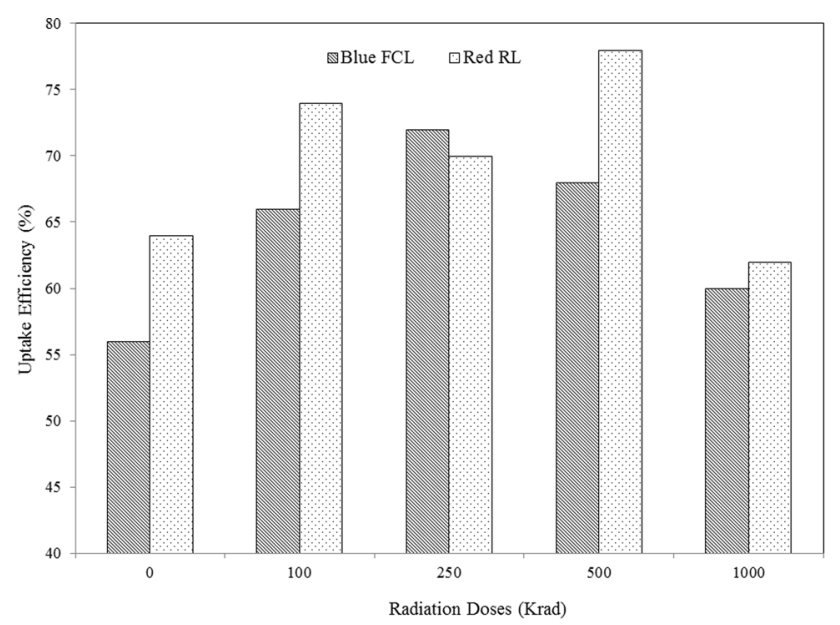

Fig. 2 Effect of gamma irradiation on the dye adsorption study of JSP

مدينة الملك عبدالعزيز KACST

\section{Adsorption capacity of differently pretreated jute stick powder}

The JSP mainly consists of cellulose and lignin, and many hydroxyl groups. All these components are active ion exchangers and based on their electron-donating nature and the electron-accepting nature which can be used to adsorb dye and other components of the effluent (Suemitsu et al. 1986; Shukla et al. 2002). In the contrary, JSP without pretreatment have smooth and hard surface indicating the presence of complex cellulose, hemicellulose and lignin framework (Reddy et al. 1990). That is why various chemical and physical treatments have been applied to break down the complex structure of JSP to improve the adsorption performance of many lignocellulosic materials (Robinson et al. 2002; Chun et al. 2004). In this study, various physico-chemical and radiation method were applied to enhance the adsorption capacity of the JSP.

Among the pretreatment methods (radiation treatment, alkali treatment, ammonia treatment, steam treatment, and $\mathrm{CaCl}_{2}$ treatment) applied in this study, radiation treatment resulted in the highest improvement of adsorbing capacity of JSP in adsorbing both the dyes, e.g., Blue FCL and Red RL used compared to others (Fig. 3). It was found that in adsorbing Blue FCL, JSP pretreated by steam treatment, $\mathrm{CaCl}_{2}$ treatment, gamma radiation and ammonia treatment showed good results, whereas steam-treated JSP showed the highest capacity $(80 \%)$ in adsorbing this dye. On the other hand, only gamma-irradiated JSP powder had the ability to adsorb more than $75 \%$ of the Red RL from $50 \mathrm{ppm}$ of its solution. The absorption rate for two dyes in case of same pretreated JSP is different (Fig. 3). Every dye has a complex structure that is different to each other and the removal efficiency depends on which dye structure binds well with the absorbent's molecular structure.

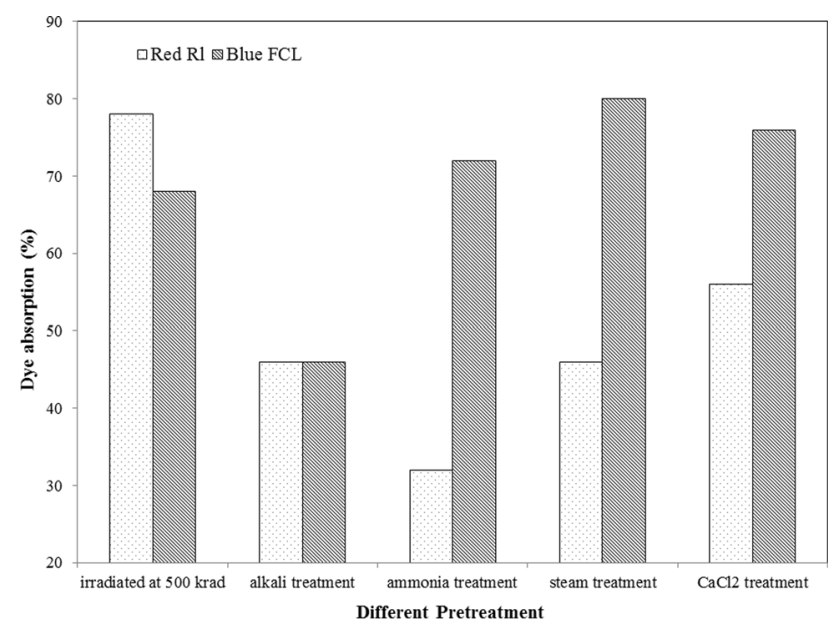

Fig. 3 Adsorption capacity of Red RL and Blue FCL on differently pretreated JSP 
So, it can be concluded that JSP exposes less functional group which was ultimately required for better adsorption capacity. However, pretreatment might provide much distorted surface properties which led to increase the surface area and the degradation of complex framework of JSP. Enhancement of surface area due to split of complex lignin framework of JSP improved the dyestuff adsorption capacity. Mechanism of dye absorption by different pretreatment is well explained elsewhere (Kadam et al. 2013; Robinson et al. 2002). Among all the pretreatment methods, though $\mathrm{CaCl}_{2}$ showed good performance, but as gamma irradiation and steam treatment showed optimum performance, so these two methods has been applied in case of real textile effluent.

\section{Kinetic study for absorption}

The rate as well as mechanism of adsorption process can be explained on the basis of kinetic study. According to Panda et al. 2009, dye adsorption on solid surface may be explained by two distinct mechanisms; (1) an initial rapid binding of dye molecules on the adsorbent surface followed by (2) relatively slow intra-particle diffusion. Progress of the adsorption of dyes by JSP with agitation time (Fig. 4) also shows that the rate of adsorption of the dye molecules was initially very fast and then gradually slows down to reach equilibrium within $1 \mathrm{~h}$. To determine the rate controlling and mass transfer mechanism, experimental kinetic data were correlated to linear form of the pseudo first and second-order rate models according to the equation described therein (Panda et al. 2009).

Experimental data show high degree of nonlinearity (figure not shown) and poor correlation coefficients $\left(r^{2}=0.51-0.61\right)$ for pseudo first-order model. On the other

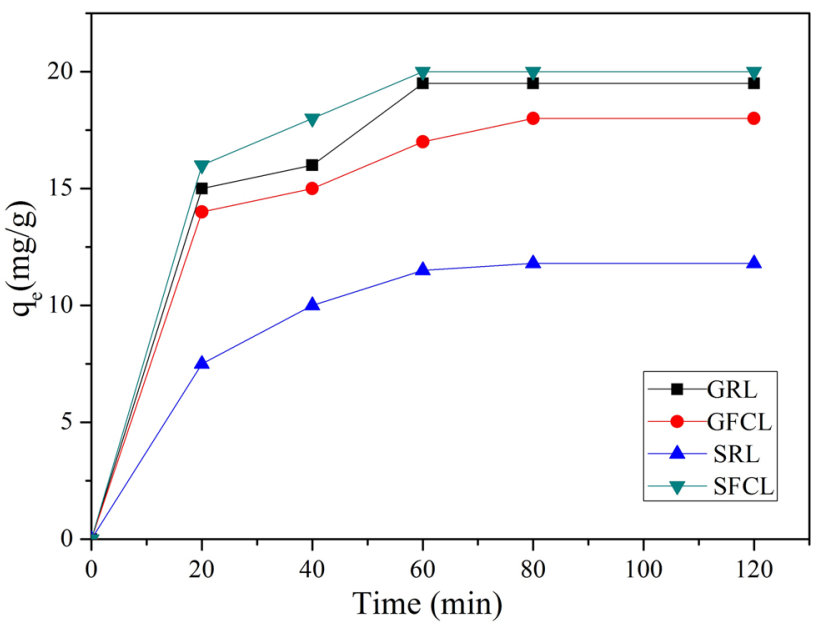

Fig. 4 Effect of contact time on Red RL dye absorption on gamma irradiated JSP (GRL) and steam treated JSP (SRL) and Blue FCL dye on gamma irradiated JSP (GFCL) and steam treated JSP (SFCL)

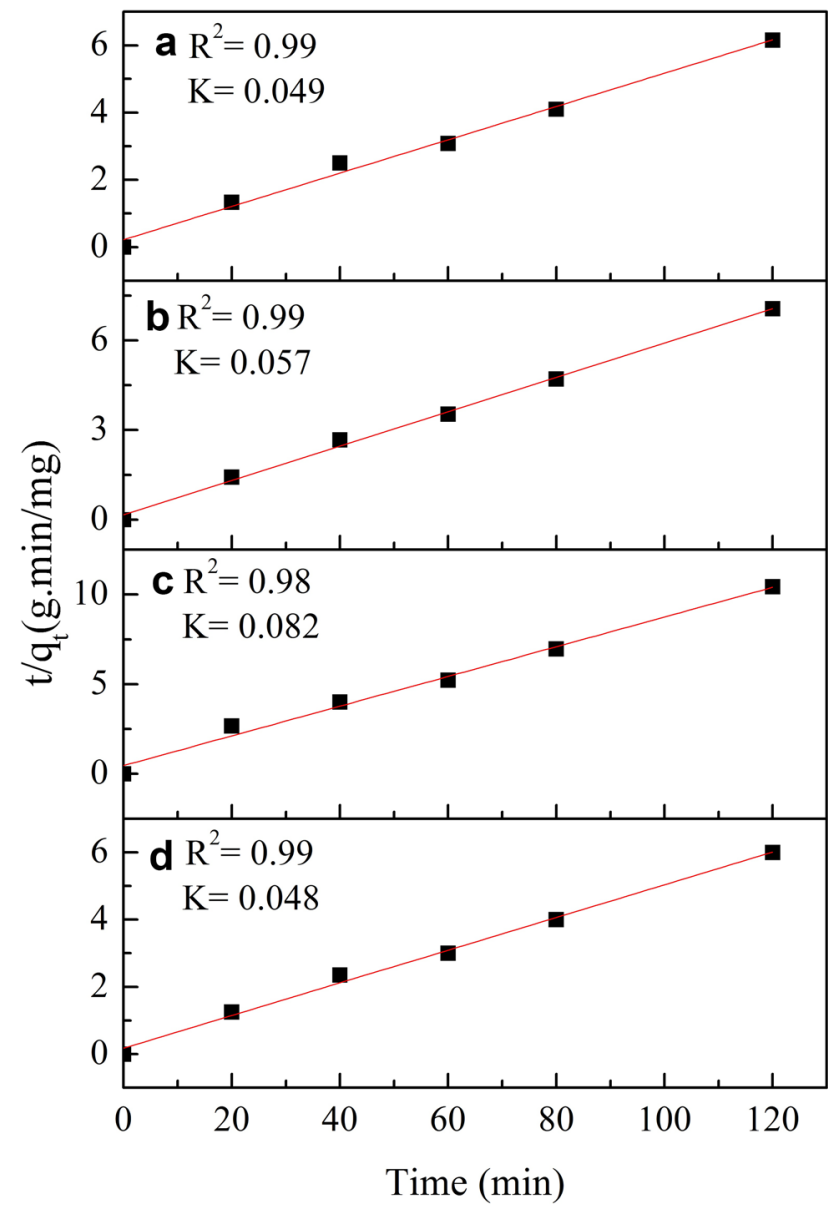

Fig. 5 Second order plot for absorption of a Red RL by gamma irradiated JSP, b Blue FCL by gamma irradiated JSP, $\mathbf{c}$ Red RL by Steam pretreated JSP, d Blue FCL dye by steam pretreated

hand, linearity (Fig. 5) with high correlation coefficients ( 0.99 for both the dyes) indicates that the present sorption process on gamma irradiated and steam-treated JSP follows second-order rate model. Transportation of the dyes from the solution phase into the pores of the adsorbent may also be considered as the rate controlling stage in batch experiments under rapid stirring condition.

\section{Analysis of absorption spectra for RTE and effluent treated by irradiated and steam treated JSP absorption spectra}

As RTE is a heterogeneous mixture of different chemicals, unlike the control dye solution, the dye adsorption efficiency of pretreated JSP will be different for RTE. Hence, after optimizing the JSP pretreatment methods and agitation time, real textile effluent (RTE) was passed through the gamma irradiated and steam-treated JSP to observe the dye removal efficiency for RTE. Absorption spectra of real textile effluent and effluent passed through irradiated and steam treated JSP was measured using a UV-visible 


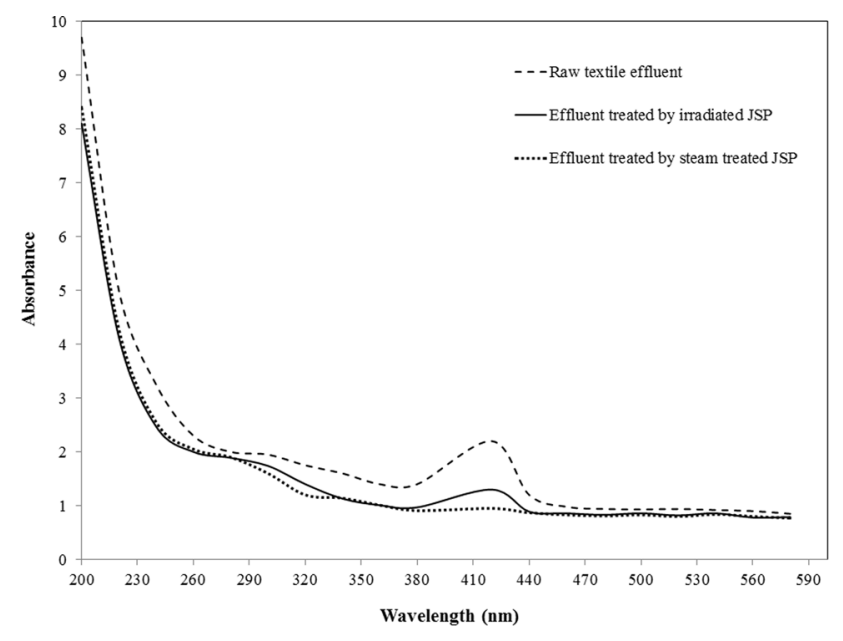

Fig. 6 Absorption spectra of RTE, effluent treated by irradiated JSP and steam treated

Spectrophotometer at (200-600) nm wavelength. The raw textile effluent had very strong absorption band in visible region at (380-440) $\mathrm{nm}$ (Fig. 6). The absorbance peak was found in this region due to the presence of violet (visible range band $380-450 \mathrm{~nm}$ ) dye present in the raw effluent collected from the textile industry. Absorption spectra were taken again for effluent after adsorption of dye by pretreated JSP (JSP irradiated with gamma radiation and steam treatment). The intensity of the absorption decreased for treated effluent within that wavelength region. The decrease of intensity reflected the reduction of concentration of the dye as the dye molecules were adsorbed by the body of the gamma irradiated and steam treated JSP.

\section{Changes in physico-chemical parameter of RTE after adsorption treatment by pretreated jute stick powder}

Removal of dyes from effluent reduces TOC, COD and BOD values (Cristóvão et al. 2010). Hence to validate the color removal capacity of pretreated JSP, we measured environmentally important parameters such as TOC, COD and BOD of RTE after adsorption on gamma irradiated and steam treated JSP. In addition, we also checked the $\mathrm{pH}$, electrical conductivity (EC), total dissolved solid (TDS), Turbidity of RTE. This study revealed that adsorption of dye by pretreated JSP was able to reduce EC, TDS, Turbidity, BOD5, COD and TOC from the effluent (Table 1). The difference in the physico-chemical characteristics of treated and untreated textile effluents may be attributed to the adsorption of chemicals in the effluent by jute stick through ion exchange and hydrogen bonding (Parihar and Malaviya 2013).

Steam-pretreated JSP showed more efficient results in reducing physico-chemical parameters compared to irradiated (500 krad) JSP (Table 1). In this study, steam-treated JSP reduced TOC, BOD and COD at 43, 33 and 23\%, respectively, whereas gamma-irradiated JSP reduced at a rate of $30,40,18 \%$. But still gamma irradiated JSP improved the properties more in comparison to control JSP. The reduction rate of TOC, BOD and COD in case of control JSP is 26,23 and $20 \%$, respectively. In another study, adsorption of dyes on steam-treated sugarcane bagasse reduced TOC of 51\% (Kadam et al. 2013). The COD and BOD5 load were reduced to 48 and $40 \%$, respectively, and this reduction rate is higher than our study. However, on that study they used $2 \mathrm{~g}$ of adsorbent, whereas we used $1 \mathrm{~g}$ of adsorbent (JSP). In another study, we used ionizing radiation for RTE (Parvin et al. 2015), where at $10 \mathrm{kGy}$ direct gamma irradiation, the $\mathrm{BOD}_{5}$ and COD reduced at a percentage of 59 and $61 \%$, respectively. In this method, the efficiency is higher compared to our results. However, when we consider about the cost, using pretreated JSP is more economical than using direct ionizing radiation on RTE.

\section{Characterization of adsorbent with FT-IR analysis}

The FTIR spectra of raw JSP and pretreated JSP after adsorption of dye were analyzed to determine the changes

Table 1 Physico-chemical parameters of textile effluent found before and after conducting adsorption process by pretreated JSP

\begin{tabular}{lccr}
\hline Physico-chemical parameters & \multicolumn{2}{l}{ Water sample taken from equalization tank } \\
\cline { 2 - 4 } & Before treatment & After adsorption by pretreated JSP & Steam treated JSP \\
\cline { 3 - 4 } & & Gamma irradiated JSP & 8.00 \\
\hline $\mathrm{pH}$ & 8.97 & 1100 & 13 \\
EC $\left(\mu \mathrm{S} \mathrm{cm}{ }^{-1}\right)$ & 1500 & 651 & 637 \\
TDS $(\mathrm{mg} / \mathrm{L})$ & 990 & 15.21 & 13.50 \\
Turbidity $(\mathrm{FTU})$ & 25.33 & 172 & 192 \\
BOD $(\mathrm{mg} / \mathrm{L})$ & 288 & $335 \mathrm{mg} / \mathrm{L}$ & $322 \mathrm{mg} / \mathrm{L}$ \\
COD $(\mathrm{mg} / \mathrm{L})$ & $409 \mathrm{mg} / \mathrm{L}$ & $61 \mathrm{mg} / \mathrm{L}$ & $49 \mathrm{mg} / \mathrm{L}$ \\
TOC $(\mathrm{mg} / \mathrm{L})$ & $87 \mathrm{mg} / \mathrm{L}$ & & \\
\hline
\end{tabular}


Fig. 7 Comparison of FTIR spectra of $a$ raw JSP, $b$ steam treated JSP, $c$ gamma

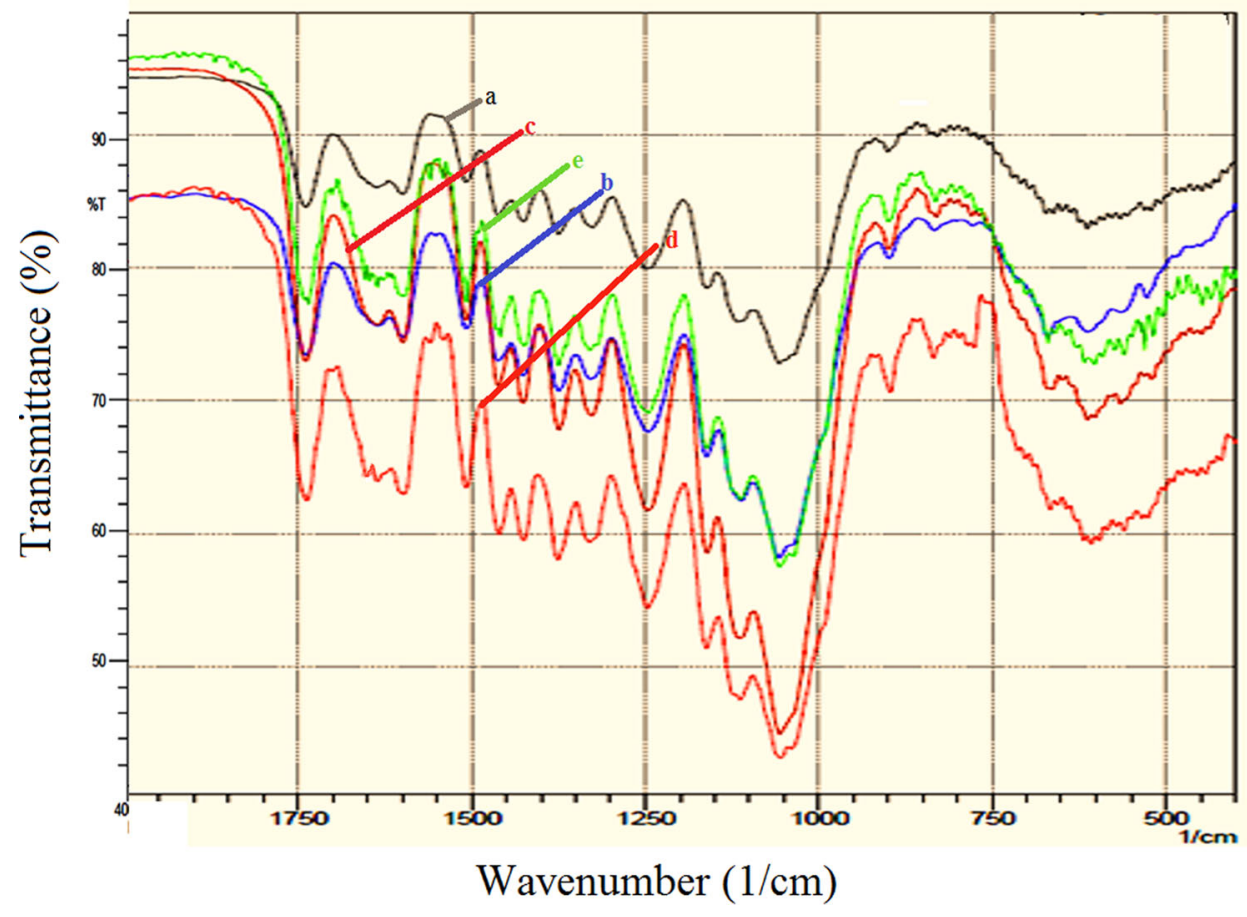

of frequency in their functional groups within the range of $2000-400 \mathrm{~cm}^{-1}$. In this study, the FTIR spectra of raw JSP, gamma irradiated and steam-treated JSP before and after conducting adsorption treatment of effluent showed characteristic peaks and the changes in the peak intensity within the wavelength range of $500-1750 \mathrm{~cm}^{-1}$. The FTIR spectra of JSP are similar to the FTIR of JSP described by other author (Sinha and Rout 2009). The characteristic features of the spectrum of the JSP (Fig. 7a) are due to its constituent's lignin, hemicelluloses and $\alpha$-cellulose. The peak number at $1737.86 \mathrm{~cm}^{-1}$ is more or less identical to $\mathrm{C}-\mathrm{O}$ stretching of the carboxyl and acetyl groups in hemicelluloses of the jute (Sinha and Rout 2009). The two sharp bands in the region 1635.64 is for $\mathrm{C}=\mathrm{C}$ stretching to the aromatic $\mathrm{C}-\mathrm{C}$ bond and $1508.33 \mathrm{~cm}^{-1}$ are most probably due to stretching modes of benzene of lignin present in JSP. The absorbance at $1460.11 \mathrm{~cm}^{-1}$ is attributed to $\mathrm{CH}_{3}$ deformation (asymmetric) in lignin. The band at $1375.25 \mathrm{~cm}^{-1}$, which is ascribed to the $\mathrm{C}-\mathrm{H}$ deforming (symmetric), may be attributed to lignin, $\alpha$-cellulose, or xylan. The medium band at $1242.16 \mathrm{~cm}^{-1}$, ascribed to C$\mathrm{O}$ stretching in acetyl in xylan, was found prominent in raw jute (Sinha and Rout 2009). Also $1161.15 \mathrm{~cm}^{-1}$ peak represents $\mathrm{C}-\mathrm{N}$ bond. However, some differences were observed in jute stick powder after steam treatment (Fig. 7b). The band at $1037.70 \mathrm{~cm}^{-1}$, which is assigned to aromatic $\mathrm{C}-\mathrm{H}$ in plane deformation and $\mathrm{C}-\mathrm{O}$ deformation for primary alcohol in lignin, was found in steam-treated JSP compared to raw JSP (Sinha and Rout 2009). In case of dye of RTE adsorbed steam treated JSP (Fig. 7d) a new peak appeared at $1649.14 \mathrm{~cm}^{-1}$ which stands for $\mathrm{N}-\mathrm{H}$ bend of $1^{\circ}$ amines. By comparing the difference between the FTIR spectra of Fig. 7b, d, it is proved that dye was adsorbed in steam treated jute stick powder. No major differences in jute stick powder were observed in the whole IR region after treatment with gamma irradiation (Fig. 7c) except some differences in peak intensities and shifting. However, after dye of RTE adsorption in gamma irradiated (500krad) JSP, two new peak appeared at $1627.92 \mathrm{~cm}^{-1}$ for $\mathrm{N}-\mathrm{H}$ bend of $1^{\circ}$ amines and $1035.77 \mathrm{~cm}^{-1}$ for $\mathrm{C}-\mathrm{N}$ stretching of aliphatic amines which indicate that dye was adsorbed in the gamma irradiated JSP (Fig. 7e).

\section{Conclusions}

It can be concluded that pretreated JSP can be a viable alternative for other costly adsorbent in adsorbing dye from textile effluent. $500 \mathrm{krad}$ was the optimum gamma irradiation dose for JSP to adsorb Blue FCL and Red RL dye. Among all the pretreatment techniques, gamma irradiated JSP (500 Krad) showed highest dye uptake capacity for Blue FCL dye, whereas steam treated JSP exhibited highest performance in adsorbing Red RL dye. Gamma irradiated (500 krad), ammonia treated, steam treated, and $\mathrm{CaCl}_{2}$ treated JSP were able to adsorb more than $70 \%$ of the Blue FCL from $50 \mathrm{ppm}$ of its solution. The adsorption process is very fast initially and the intra-particle diffusion to reach equilibrium within $1 \mathrm{~h}$ followed pseudo-second-order rate kinetics. The absorbance intensity of UV-Vis absorption

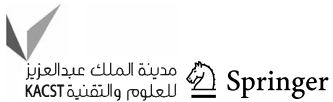


spectra of RTE confirmed reduction of dye concentration due to the adsorption of dye molecules on the pretreated JSP, which was again confirmed by analyzing the FTIR spectra. Improvement of the environmentally important parameters of RTE were found after performing adsorption on pretreated (gamma irradiated at $500 \mathrm{krad}$ and steam treatment) JSP which is an extra advantage in using JSP in dye removal. However, by comparing with other study, it can be recommended to use more than $1 \mathrm{~g}$ of the adsorbent for the $50 \mathrm{ml}$ of RTE. The data may be useful for designing and fabrication of an economically cheap treatment process using batch or stirred tank flow reactors for the removal of dye from diluted industrial effluent. But before this it is necessary to explore the effect of temperature and $\mathrm{pH}$ change on dye absorption efficiency.

Open Access This article is distributed under the terms of the Creative Commons Attribution 4.0 International License (http:// creativecommons.org/licenses/by/4.0/), which permits unrestricted use, distribution, and reproduction in any medium, provided you give appropriate credit to the original author(s) and the source, provide a link to the Creative Commons license, and indicate if changes were made.

Publisher's Note Springer Nature remains neutral with regard to jurisdictional claims in published maps and institutional affiliations.

\section{References}

Chatterjee S, Chatterjee BP, Das AR, Guha AK (2005) Adsorption of a model anionic dye, eosin $\mathrm{Y}$, from aqueous solution by chitosan hydro beads. J Colloid Interface Sci 288:30-35. doi:10.1016/j. jcis.2005.02.055

Chun L, Hongzhang C, Zuohu L (2004) Adsorption of Cr(VI) by Fe modified steam exploded wheat straw. Process Biochem 39:541-545. doi:10.1016/S0032-9592(03)00087-6

Crini G (2006) Non-conventional low-cost adsorbents for dye removal: a review. Bioresour Technol 97(9):1061-1085. doi:10.1016/j.biortech.2005.05.001

Cristóvão R, Tavares APM, Loureiro JM, Boaventura RAR, Macedo EA (2010) Treatment and kinetic modeling of a simulated dye house effluent by enzymatic catalysis. Bioresour Technol 100:6236-6242

Fu Y, Virarahavan T (2001) Fungal decolorization of dye wastewater. A review. Bioresour Technol 79:251-262. doi:10.1016/S09608524(01)00028-1

Hildenbrand S, Schmahl FW, Wodarz R, Kimmel R, Dartsch PC (1999) Azo and carcinogenic aromatic amines in cell cultures. Int Arch Occup Environ Health 72(3):M052-M056. doi:10.1007/ PL00014217
Islam JMM, Habib SMA, Parvin F, Rahman MF, Saadat AHM, Khan MA (2013) Removal of industrial dye effluent (Drimarene Yellow) by renewable natural resources. Am Acad Scholar Res J 5(2): 144

Kadam AA, Lade SH, Patil SM, Govindwa SP (2013) Low cost $\mathrm{CaCl}_{2}$ pretreatment of sugarcane bagasse for enhancement of textile dyes adsorption and subsequent biodegradation of adsorbed dyes under solid state fermentation. Bioresour Technol 132:276-284. doi:10.1016/j.biortech.2013.01.059

Panda GC, Das SK, Guha AK (2009) Jute stick powder as a potential biomass for the removal of congo red and rhodamine B from their aqueous solution. J Hazard Mater 164:374-379. doi:10. 1016/j.jhazmat.2008.08.015

Parihar A, Malaviya P (2013) Textile wastewater treatment using sawdust as adsorbent. Int J Environ Sci 2(3):110-113

Parvin F, Ferdaos Z, Tareq SM, Choudhury TR, Islam JMM, Khan MA (2015) Effect of gamma irradiated textile effluent on plant growth. Int J Recycl Org Waste Agric 4:23. doi:10.1007/s40093014-0081-Z

Pekel N, Yoshii F, Kume T, Guven O (2004) Radiation crosslinking of biodegradable hydroxypropyl methyl cellulose. Carbohydr Polym 55:139-147. doi:10.1016/j.carbpol.2003.08.015

Reddy SS, Bhaduri SK, Sen SK (1990) Infrared spectra of alkali treated jute stick. J Appl Polym Sci 41:329-336. doi:10.1002/ app.1990.070410125

Robinson T, Chandran B, Nigam P (2002) Effect of pretreatments of three waste residues, wheat straw, corncobs and barley husks on dye adsorption. Bioresour Technol 85:119-124. doi:10.1016/ S0960-8524(02)00099-8

Saraswathi K, Balakumar S (2009) Biodecolourization of azodye. (pigmented red 208) Bacillus firmus and Bacillus laterosporus. J Biosci Tech 1(1):1-7

Senthilkumaar S, Subburaam CV, Kalaamani P, Porkodi K, Varadarajan PR (2006) Adsorption of dissolved reactive red dye from aqueous phase onto activated carbon prepared from agricultural waste. Bioresour Technol 97(4):1618-1625. doi:10.1016/j. biortech.2005.08.001

Shukla A, Zhang YH, Dubey P, Margrave JL, Shukla SS (2002) The role of sawdust in the removal of unwanted materials from water. J Hazard Mater 95(1-2):137-152. doi:10.1016/S03043894(02)00089-4

Sinha E, Rout SK (2009) Influence of fibre-surface treatment on structural, thermal and mechanical properties of jute fibre and its composite. Bull Mater Sci 32(1):65-76. doi:10.1007/s12034009-0010-3

Suemitsu R, Osako M, Tagiri N (1986) Use of dye-treated sawdust for removal of heavy metals from wastewater. Sci Eng Rev 27:41-48

Wach RA, Mitomo H, Nagasawa N, Yoshii F (2003) Radiation crosslinking of carboxymethylcellulose of various degree of substitution at high concentration in aqueous solutions of natural pH. Radiat Phys Chem 68(5):771-779. doi:10.1016/S0969806X(03)00403-1 